\title{
Anti-microbial Activities of Pseudomonas Metabolites Methanolic Extracts against Different MDR Bacterial Pathogens
}

\author{
Ubaid Rasheed $^{1 *}$, Faiza Momin ${ }^{1 \#}$, Hikmat Ullah $^{1}, \operatorname{Imad~Ali}^{1}$, Haq Nawaz $^{1}$, Latif Ahmad ${ }^{1}$, Abid Khan and \\ Mahideen Afridi $^{3}$ \\ ${ }^{1}$ Kohat University of Science and Technology, Department of Microbiology \\ Kohat, Pakistan \\ ${ }^{2}$ Center of Biotechnology \& Microbiology (COBAM), University of Peshawar \\ Peshawar, Pakistan
}

${ }^{3}$ National Center for Bioinformatics, Quaid-i-Azam University Islamabad, Pakistan

*Corresponding author's email: ubaidrasheed3 [AT] gmail.com

${ }^{\#}$ Corresponding author's email: faizamomin12 [AT] gmail.com

\begin{abstract}
---
Background: A Multiple drug resistance (MDR) in pathogenic bacteria has become a significant public health issue for treatment. Among bacteria, Pseudomonas is another important genus except Streptomyces and Bacillus in production of antimicrobial compounds. The current study aim to to determine the antibacterial activity and preliminary characterization of antibacterial compounds produced by Pseudomonas species such as BB1D11, BN2D41, TG1D11, TR1D41, LH1D11 and TN1D41.

Method: The antibacterial activity was checked by using bio autography method as well as agar well diffusion method, against four multiple drug resistant bacteria including three Gram negative bacteria (E.coli, Acinetobacter and Pseudomonas) and one Gram positive bacterium (Methicillin Resistant Staphylococcus aureus). Isolation test showed good activity against all the four MDR bacteria, by producing clear zone of diameter from $2 \mathrm{~mm}$ up to 20mm. Optimum temperature for growth and antibiotic production of Pseudomonas BB1D11, BN2D41, TG1D11, TR1D41, LH1D11 and

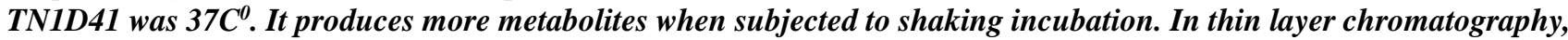
the extracts were repeatedly inserted on a silica gel coated plate, which was run in mobile phase. Normal HPLC was perform to reveal the presence of antibacterial compounds.

Results: By well diffusion assay a zone of inhibition range from 2-18 $\mathrm{mm}$ of diameter against different test bacteria. The components were separated, resulting in the formation of bands with different colors, each showing a different compounds. Biological screening was performed by bio autography, metabolites showed a significant activity at retention factor of 0.89 . While HPLC at retention time 2.50-2.90 showed presence of significant antibacterial compounds.

Conclusion: Pseudomonas BB1D11, BN2D41, TG1D11, TR1D41, LH1D11 and TN1D41 showed promising antimicrobial activity against different MDR bacteria. It is concluded that HPLC revealed the presence of DAPG at retention time 2.90 which inhibit the growth of MDR bacterial strains.
\end{abstract}

Keywords: MDR, Pseudomonas, Streptomyces, Bacillus and TLC

\section{INTRODUCTION}

Multidrug resistant bacteria is one of the most important public health problems currently. In American society such as infectious disease society of America (IDSA) identifies an antimicrobial resistance to treats the human health worldwide (1). Several problems trigger the severe vulnerability which is stood due to high level of MDR bacteria (2). The most important results in patient infected by MDR bacteria tend to be badly as compared to patient infected with susceptible organism. In this way, the high level of antibiotics resistant's effect of the new medicine and danger to reduce the activities of cancer disease, kidney transplantation and many other surgeries as well as their price are increased day by day $(3,4)$. However, MDR are related with nosocomial infection which leads to a community-acquired infection. The increasing level of MDR bacteria cause risk at population and mostly increase the quantity of infection in community population(5).

Furthermore, MDR bacteria that are effective in the community have to be capable to continue lacking of biofilm on inorganic compound. The biofilm production is important pathophysiologic constituent of periodontal infection, stomach infection with H.pylori middle ear infection, UTI, throat infection and other infection. MDR bacteria have the capability to develop the biofilm without of foreign particles in a community (6). 
When microorganisms start growing in the presence of antibiotics, it is known as microbial resistance to antibiotic. The potential for antibiotic resistance was recognized in the early 1940s, almost immediately after the first large-scale clinical applications of penicillin, the first antibiotic [7]. Antibiotic resistance is gained by two types of genetic mechanisms: mutation and acquisition of new genetic material [8,9]. Examples of the former type are chloramphenicol-acetylating staphylococci and penicillin-inactivating staphylococci [10]. In the last three decades, as the number of antibiotics increased, bacterial resistance against antibiotics also reached to its peak, which leads to serious problems [11].

Antibacterial agents showed good activity, initially, but its effect reduced slowly with time, as many bacteria became resistant to these antibiotics. There are also bacteria which are resistant to multiple antibiotics. These bacteria are called super bugs [12]. The most well-known example of super bug is Methicillin resistant Staphylococcus aureus (MRSA). 53 million people are carriers of MRSA globally according to survey conducted in 2006 and this number is increasing day by day [13]. Vancomycin has been the therapeutic option to treat MRSA, but vancomycin resistant S. aureus (VRSA) have emerged clinically very rapidly because MRSA also develops resistant to vancomycin [14]. The development of "panresistant" of bacterial strains, specially strains of Pseudomonas aeruginosa and Acinetobacter baumannii, occurred more recently, after most major pharmaceutical companies stopped the development of new antibacterial agents [15]. It was proposed in 1973 that the microorganisms which produce antimicrobial components have a main role in producing antibiotic-inactivating enzymes for their own protection [16]. Some environmental bacteria contain natural antibiotic resistance genes, like the soil Pseudomonas aeruginosa [17]. The main reason of multiple drug resistance is the misuse (overuse) of antibiotics [18].

Pseudomonas spp. also produces bioactive metabolites. Mupirocin free acid (produced by Pseudomonas), and its salts and esters are agents currently used in creams, ointments, and sprays as a treatment of Methicillin-resistant Staphylococcus aureus infection [19].

Antibiotic producing bacteria are gaining importance by many investigators as bio control agents against pathogenic bacteria [20,21]. Pseudomonas sp. isolated from soil showed antimicrobial activity against some pathogenic bacteria $S$. aureus [22]. Similarly, other MDR strains are also found to be susceptible to metabolites, produced by Pseudomonas putida [23].

The objective of this study is to the protective effect of anti-microbial activities of Pseudomonas methanolic extracts against different MDR bacterial pathogens.

\section{MATERIAL AND METHODS}

Pseudomonas spp. $\left(B B_{1} D_{1} 1, B N_{2} D_{4} 1, T G_{1} D_{1} 1, T R_{1} D_{4} 1, L H_{1} D_{1} l\right.$ and $\left.T N_{1} D_{4} l\right)$ were checked. The samples were identified by Gram staining and biochemical tests.

Extraction of crude secondary metabolites with organic solvent: Crude metabolites were extracted from culture of six different strain of pseudomonas grow in $200 \mathrm{ml}$ of nutrient broth in a shaking incubator for 48 hours at $37{ }^{\circ} \mathrm{C}$ then mixed with ethyl acetate in the ratio of 1:1 sonicated for 15 minutes in a sonicating bath (UltrasonsMedi-II) to break all the cells. The dead cells layer were separated by separating funnel Cell free layer having ethyle acetate and metabolites were collected in a flask and subjected to the rotary evaporator (Heidolph Laborata 4000). The crude extracts of active compounds remained stuck to the bottom of rotatory evaporator, which were mixed in methanol and were collected in clean glass tubes.

Antibacterial activity (well diffusion method): Antibacterial activity of crude extracted metabolites: Test bacteria MRSA, Escherichia coli, pseudomonas aeruginosa and acintobacter baumannii were obtained from department microbiology KUST and maintained by sub-culturing on Nutrient Agar. Methanolic extract extracted from six different strain of pseudomonas were tested by Agar well diffusion method for their activity against MDR bacterial pathogens (Valgas et al. 2007). The prepared culture plates were inoculated with different test bacteria using plate method. Wells were made on the agar surface with $6 \mathrm{~mm}$ cork borer. Bacterial lawn of test organisms were formed by sterile swab on muller hinton agar, each. Six wells of diameter $6 \mathrm{~mm}$ were made in each plate by cork borer. The $50 \mu \mathrm{l}$ of methanol extracts was poured in each well by micropipettes. The plates were left for 5 minutes and then incubated at $37^{\circ} \mathrm{C}$ for 24 hours. The zone were observed around the wells.

Detection of metabolites by thin layer chromatography: $20 \mu \mathrm{l}$ of sample were spotted on thin layer chromatographic column coated with silica gel. The spotted plate were transfer to gel tank having organic solvent chloroform: acetic acid (95:5) after 30 minutes of capillary movement of organic solvent on silica plate the spotted plate were observed under UV of $260 \mathrm{~nm}$ and $280 \mathrm{~nm}$ as well sprayed by Spraying reagent Anisaldehyde/ $\mathrm{H}_{2} \mathrm{SO}_{4}$ and Spraying Ehrlich reagent

High performance liquid chromatography (HPLC): HPLC were performed to detect the retention time of secondary metabolites of various strains of pseudomonas bacterial. Before the investigation methanolic extract were dissolved in a DMSO. $20 \mu \mathrm{l}$ methanolic crude extract were injected into the HPLC equipped with silica column $(5 \mu \mathrm{m} ; 4.6 \times 150 \mathrm{~mm})$ and 
eluted at $1 \mathrm{ml} / \mathrm{min}$. initially, $80 \%$ acetonitrile/ water (v/v, both acidified with $0.1 \%$ acetic acid), was run for 2 min then $80 \%$ acetonitrile (acidified with $0.1 \%$ acetic acid) run for 32 minute period. The HPLC mobile-phase consisted of Acetonitrile: Water (80:20) at a flow rate of $0.8 \mathrm{ml} / \mathrm{min}$ and detected at a wavelength of $254 \mathrm{~nm}$. Resolutions results may vary from column to column.

\section{RESULTS AND DISCUSSION}

Extraction of secondary metabolites: protocols for most of the secondary metabolites extraction are well known and they are produce during growth and stationary phases at higher rate [24]. Reported literature presented that Pseudomonas strains are at third number producers of secondary metabolites with highest antimicrobial activities [25, 26]. In current study, different pseudomonas strains were found that produces Secondary Metabolites (SM).

Already describing protocols for the extraction of secondary metabolites making it more easy with choice of extraction procedure such as the process of liquid-liquid extraction are vastly applicable for compounds isolation by the use of different solvents such as ethyl acetate and chloroform [27]. In current the methanol was found best solvent to dissolve metabolites of pseudomonas strains which show protection against bacterial MDR.

Antibacterial activity of secondary metabolites (SM) The crude methanolic extract of SM isolated from P.fluorescens $(B B 1 D 1)$ showed a zone of inhibition, i.e $03 \mathrm{~mm}$ against $A$. baumannii, $02 \mathrm{~mm}$ against MRSA, $04 \mathrm{~mm}$ against $P$. aeruginosa and having no activity against $E$. coli while the methanolic extract of p. auregenosa (BN2D41) present zone of inhibition i.e. $04 \mathrm{~mm}$ against $A$. baumannii, $03 \mathrm{~mm}$ against MRSA, $05 \mathrm{~mm}$ against E. coli and $03 \mathrm{~mm}$ again p. aeruginosa whereas $p$. putida $\left(T G_{l} D_{l} l\right)$ produced zone of inhibition i.e $16 \mathrm{~mm}$ against $A$. baumannii, 06 against MRSA, 08 against E. coli and 05 against $p$. aeruginosa. As shown in figure 1 .

The crude methanolic extract obtained from P.flourescens (TR1D41) showed a zone of inhibitions i.e $15 \mathrm{~mm}$ against $A$. baumannii, $06 \mathrm{~mm}$ against MRSA, $08 \mathrm{~mm}$ against $E$. coli and $18 \mathrm{~mm}$ against $P$. aeruginosa. While another P.flourescens (LH1D11) strain metabolites presented zone of inhibition i.e. $08 \mathrm{~mm}$ against $A$. baumannii, $08 \mathrm{~mm}$ against MRSA, $05 \mathrm{~mm}$ against E. coli and 04mm against p. auregenosa as shown in figure 1.

Another $P$. putide (TN1D41) strain extracted SM showed inhibition zones i.e. $12 \mathrm{~mm}$ against $A$. baumannii, $05 \mathrm{~mm}$ against MRSA, 05mm against $E$. coli and $06 \mathrm{~mm}$ against $p$. auregenosa as shown in figure 1 .

Recent finding presented that pseudomonas metabolites have efficient activity against bacillus subtiles, Paracoccus paratrophus, Pseudomonas diminutus and Micrococcus luteus with zones of inhibition of $15 \mathrm{~mm}, 25 \mathrm{~mm}, 8 \mathrm{~mm}$ and $3 \mathrm{~mm}$ respectively [28]. According to Sunker and Nachiyar (2013) [29] showed that Pseudomonas aeruginosa have promising bacterial inhibition activity against Staphylococcus aureus, Escherichia coli and Salmonella typhi. The antibacterial activity of 2,4-diacetylphloroglucinol (2,4-DAPG) extracted from Pseudomonas fluorescens was interpreted against 23 vancomycin resistant Staphylococcus aureus (VRSA) and Enterococcus spp. [30].

Figure 1. Antibacterial inhibition of pseudomonas metabolites against MDR.

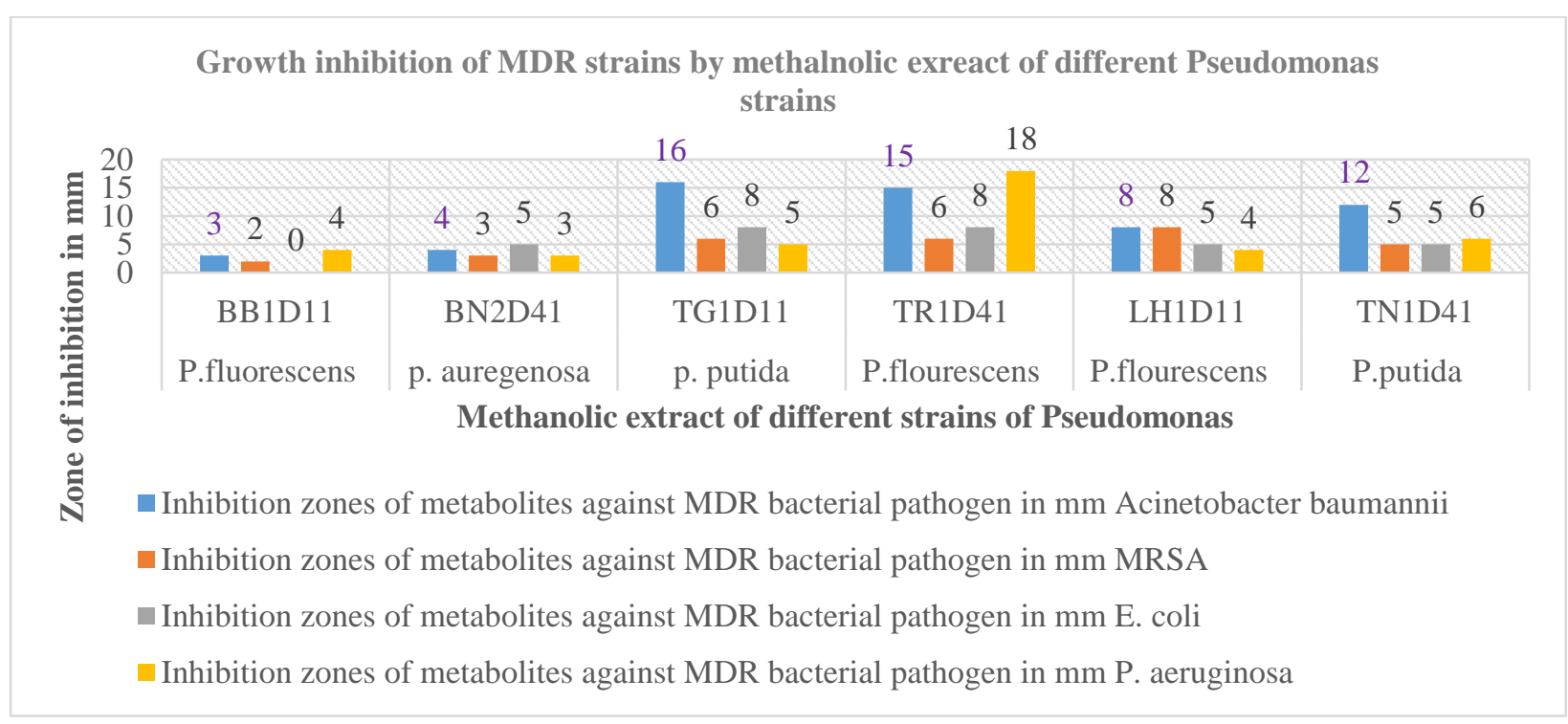


Identification of metabolites by TLC

TLC bands visualized under $280 \mathrm{~nm}$ light

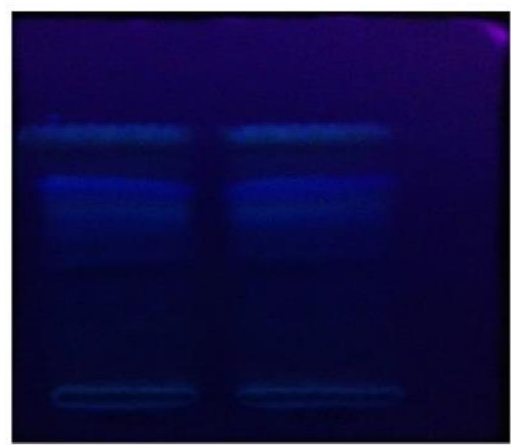

TR1D41

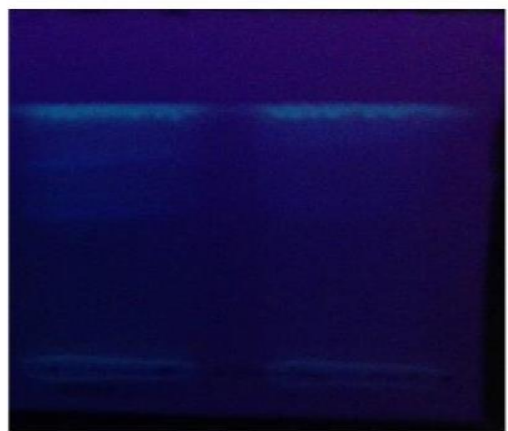

L. I 1 D 11

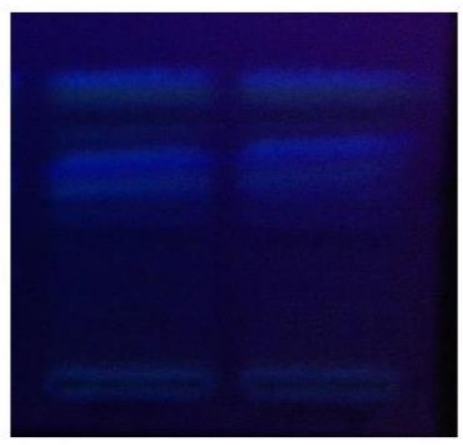

TN1D41

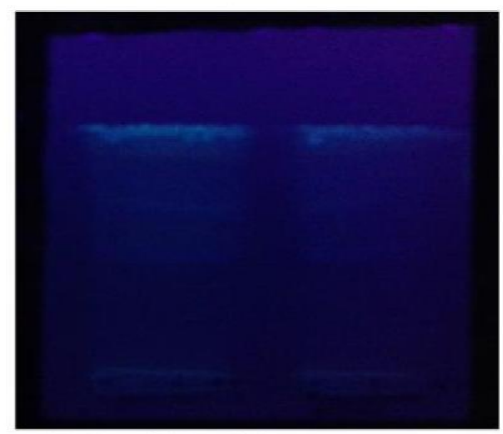

BN2D41

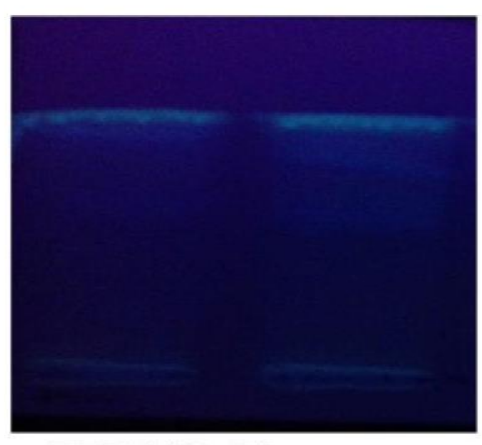

TG1D41

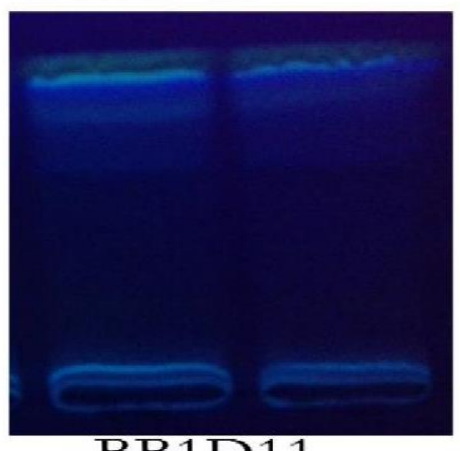

BB1D11

TLC bands visualized under 260nm light

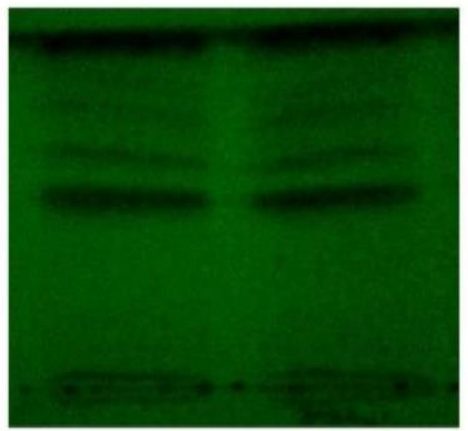

TR1D41

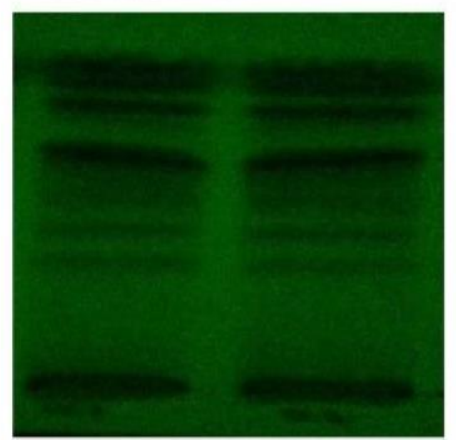

LH1D 11

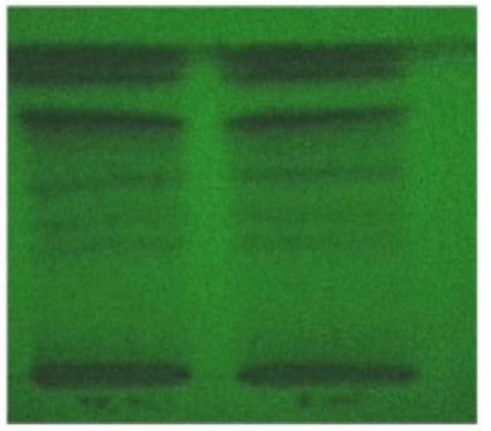

TN1D41

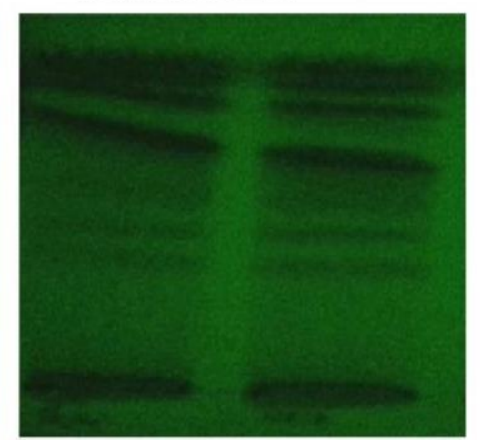

BN2D41

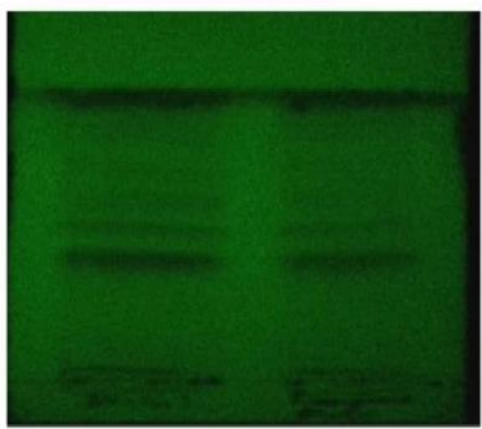

TG1D41

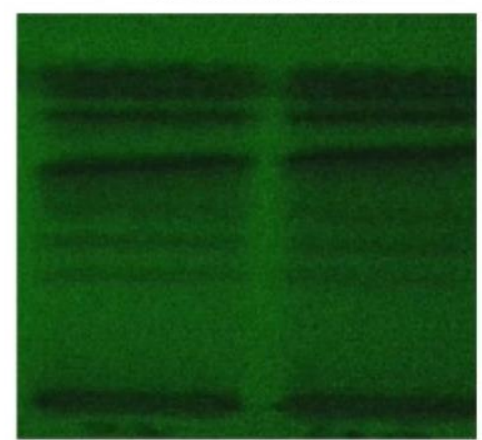

BB1D1 1 


\section{Bio-autography}

The methanolic extract of various strains of pseudomonas species were screened by thin layer of silica gel the crude secondary metabolites of different strains showed different spot at retention factors (Rf) i.e $\mathrm{TR}_{1} \mathrm{D}_{4} 1 \mathrm{Rf}$ range from 0.89 to $0.97, \mathrm{TN}_{1} \mathrm{D}_{4} 1 \mathrm{Rf} 0.89$ and $\mathrm{BB}_{1} \mathrm{D}_{1} 1 \mathrm{Rf} 0.98$ showed significant results while rest of the compounds have non-significant values. The antibacterial compounds were confirm i.e . 2, 4-DAPG, Pyrrolnitrin and Phenazine at the Rf range of 0.89 to 0.98 produces by $\mathrm{TR}_{1} \mathrm{D}_{4} 1, \mathrm{TN}_{1} \mathrm{D}_{4} 1$ and $\mathrm{BB}_{1} \mathrm{D}_{1} 1$ respectively. They present closed relevance to the $\mathrm{R} f$ value of synthetic 2,4-diacetyl phloroglucinol (0.81-0.89) and spots $\mathrm{R} f$ value vary from 0.5 to 0.80 have closed $\mathrm{R} f$ value of synthetic phenazine (0.10 and 0.89) Earlier, three strains (PF1, FP7 and PB2) were stated to yield 2,4-DAPG which had the similar $\mathrm{R}_{f}$ value as synthetic phloroglucinol (0.76) [31]. Distinct spots of 2,4-DAPG were reported to have Rf of 0.88 that visualized on the TLC plate after spraying by diazotized sulphanilic acid [32]). Secondary metabolite secreted by Pseudomonas brassicacearum $\mathrm{J} 12$ with $R f$ value of 0.10 was characterized as 2,4-DAPG which inhibited the growth of phytopathogenic bacteria Ralstonia solanacearum [33]. The zone of inhibition shown by TLC column of TR $\mathrm{D}_{4} 1$ on agar plate i.e $12 \mathrm{~mm}$ against Acinetobacter baumannii, $8 \mathrm{~mm}$ against E. coli, $4 \mathrm{~mm}$ against MRSA, $2 \mathrm{~mm}$ against $P$. aeruginosa while $\mathrm{TN}_{1} \mathrm{D}_{4} 1$ and $\mathrm{BB}_{1} \mathrm{D}_{1} 1$ shown zone of inhibition against Acinetobacter baumannii 2 mm and $4 m m$ respectively. The significant results shown by $\mathrm{TR}_{1} \mathrm{D}_{4} 1$ TLC column on agar plates as shown table 1 . The bio autographic analysis of pseudomonas metabolites against MDR strains.

Table .1. Bio autographic analysis of metabolites of pseudomonas against MDR

\begin{tabular}{|c|l|l|l|}
\hline Isolate code & Rf value & Zone of inhibition & Susceptible MDR \\
\hline $\mathrm{TR}_{1} \mathrm{D}_{4} 1$ & 0.91 & $12 \mathrm{~mm}$ & Acinetobacter baumannii \\
\hline $\mathrm{TR}_{1} \mathrm{D}_{4} 1$ & 0.89 & $8 \mathrm{~mm}$ & Escherichia coli \\
\hline $\mathrm{TR}_{1} \mathrm{D}_{4} 1$ & 0.97 & $4 \mathrm{~mm}$ & MRSA \\
\hline $\mathrm{TR}_{1} \mathrm{D}_{4} 1$ & 0.10 & $2 \mathrm{~mm}$ & Pseudomonas aeruginosa \\
\hline $\mathrm{TN}_{1} \mathrm{D}_{4} 1$ & 0.89 & $2 \mathrm{~mm}$ & Acinetobacter baumannii \\
\hline $\mathrm{BB}_{1} \mathrm{D}_{1} 1$ & 0.98 & $4 \mathrm{~mm}$ & Acinetobacter baumannii \\
\hline
\end{tabular}

\section{High performance liquid chromatography}

The crude methanolic extract shown promising activity against different test MDR organism. The secondary metabolites were subjected to HPLC for further identification and characterization. The key compound revealed at the retention time at HPLC 2.50, 2.6 and 2.90 and Rf factor of metabolites range from 0.89 to 0.98 revealed the presence of DAPG as shown in below figures. $P$. fluorescens and challenge metabolites eluted at retention time ranging from $20.00 \mathrm{~min}$ to $21.30 \mathrm{~min}$ in HPLC and $R f$ value 0.88 in TLC developed by acetonitrile : methanol : water (1:1:1) solvent system [34].

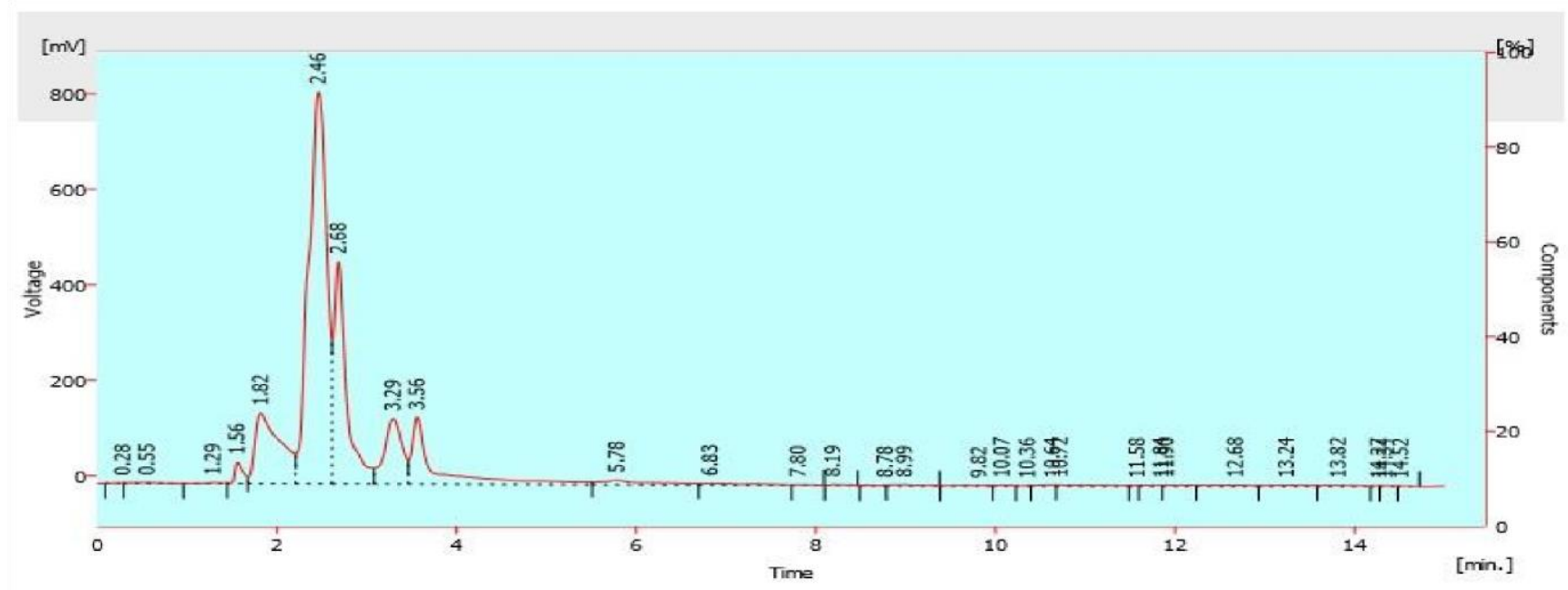

\section{Chromatogram of $\mathrm{BB}_{1} \mathrm{D}_{1} 1$}




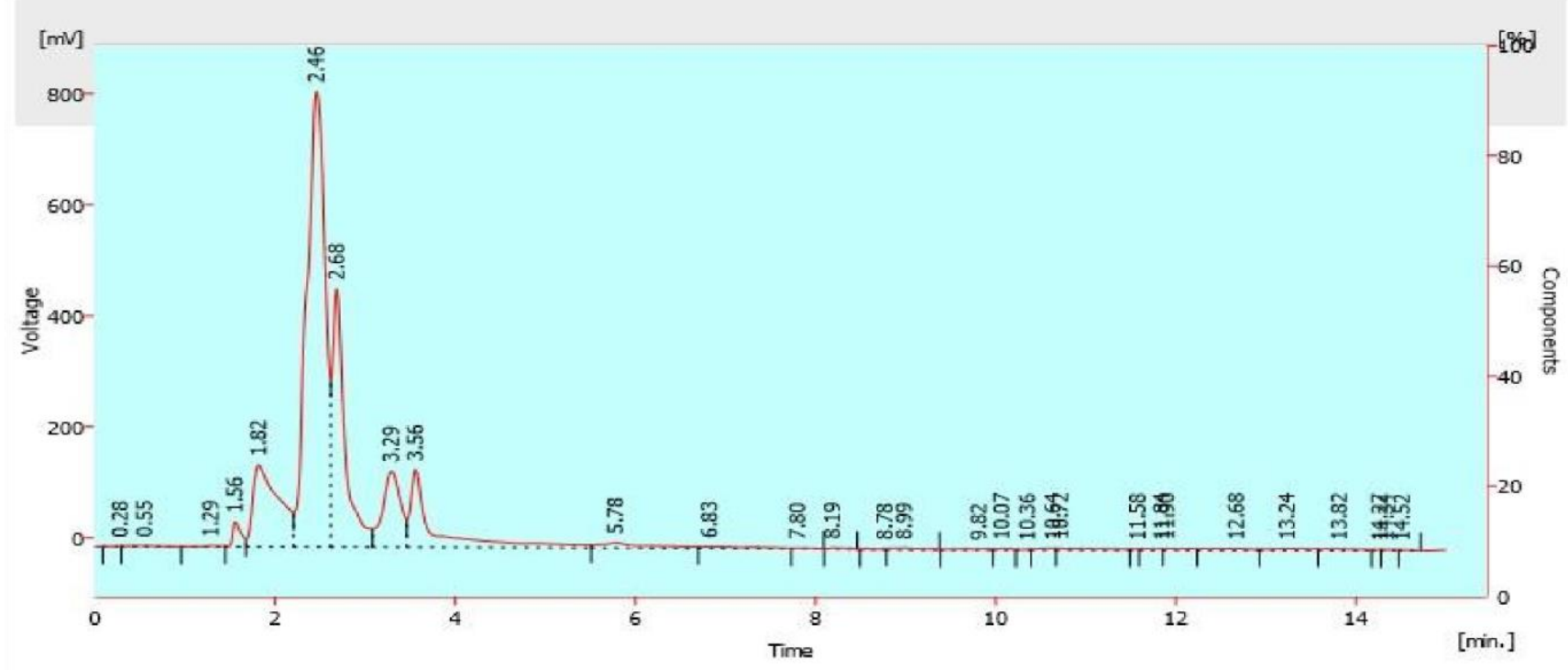

Chromatogram of $\mathrm{TR}_{1} \mathrm{D}_{4} 1$

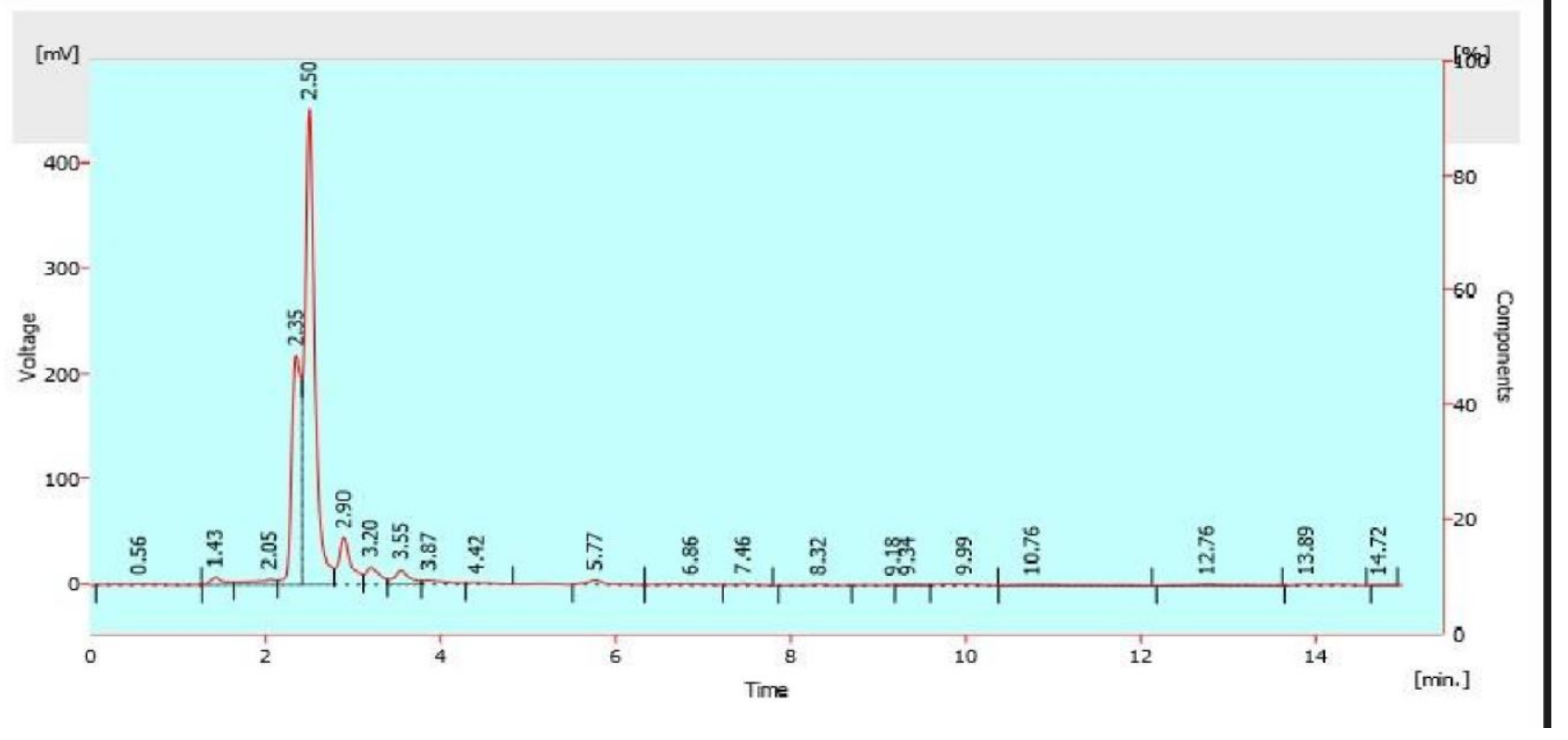

Chromatogram of $\mathrm{BN}_{2} \mathrm{D}_{4} 1$ 


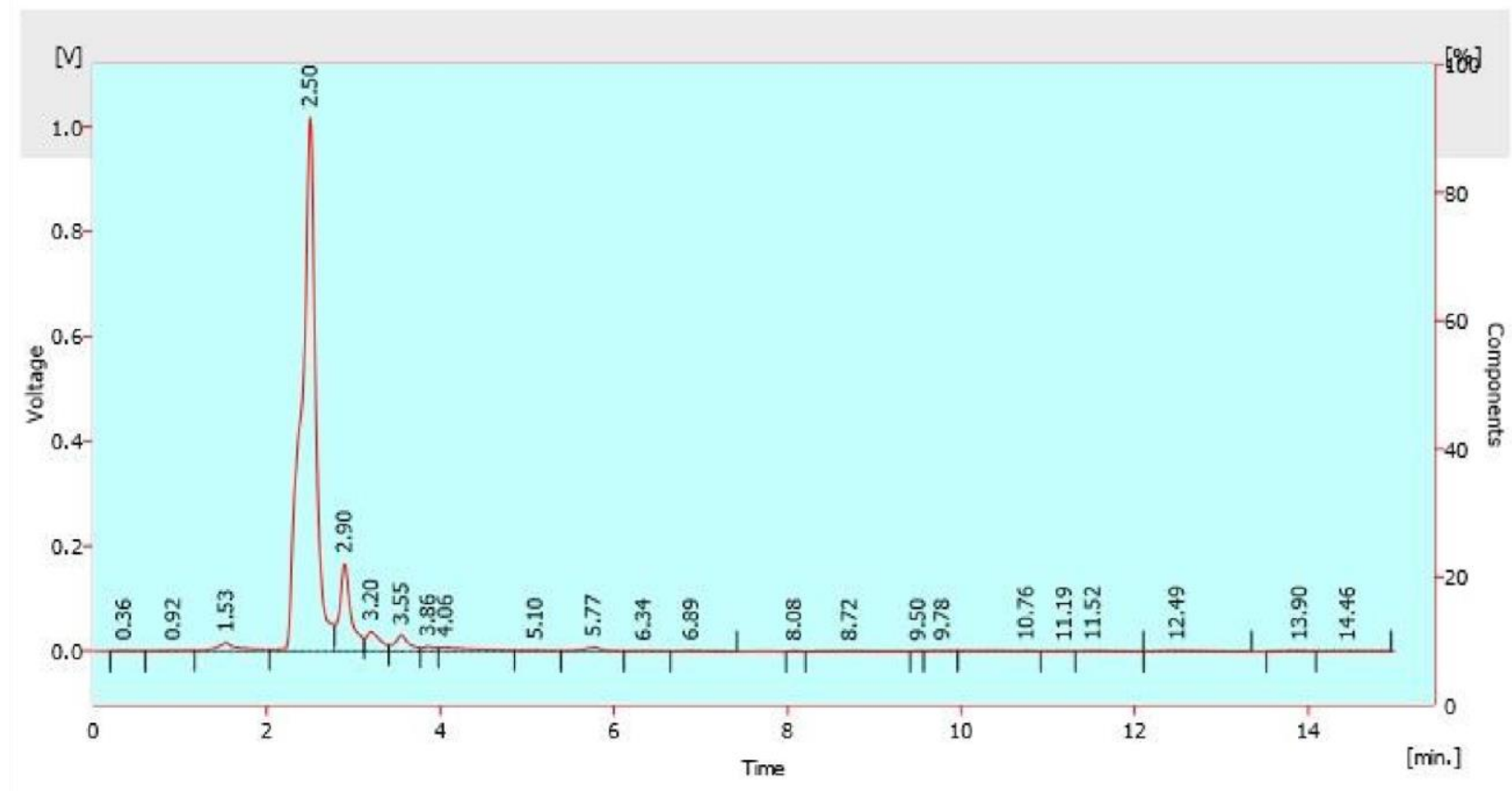

\section{Chromatogram of $\mathrm{LH}_{1} \mathrm{D}_{1} 1$}

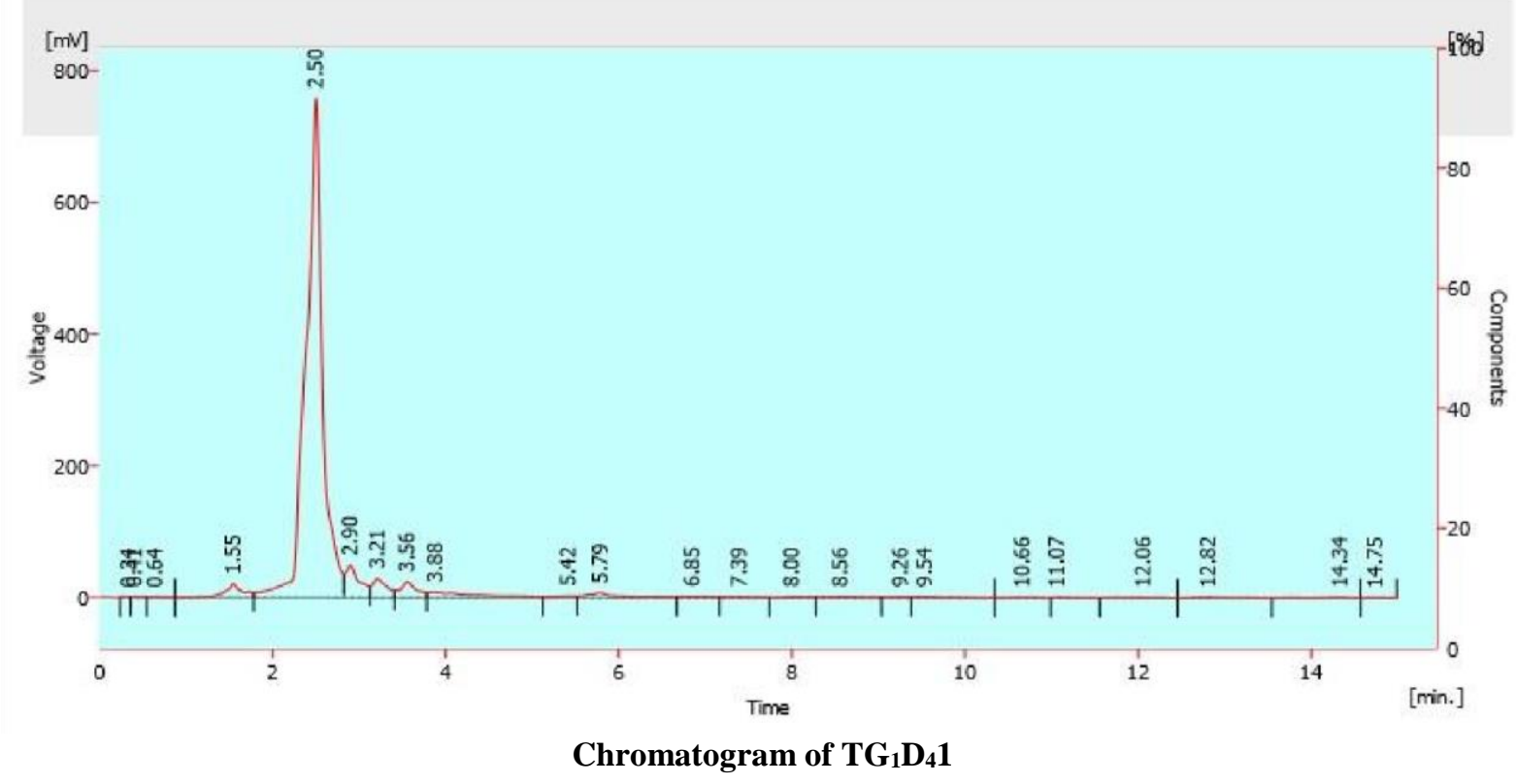




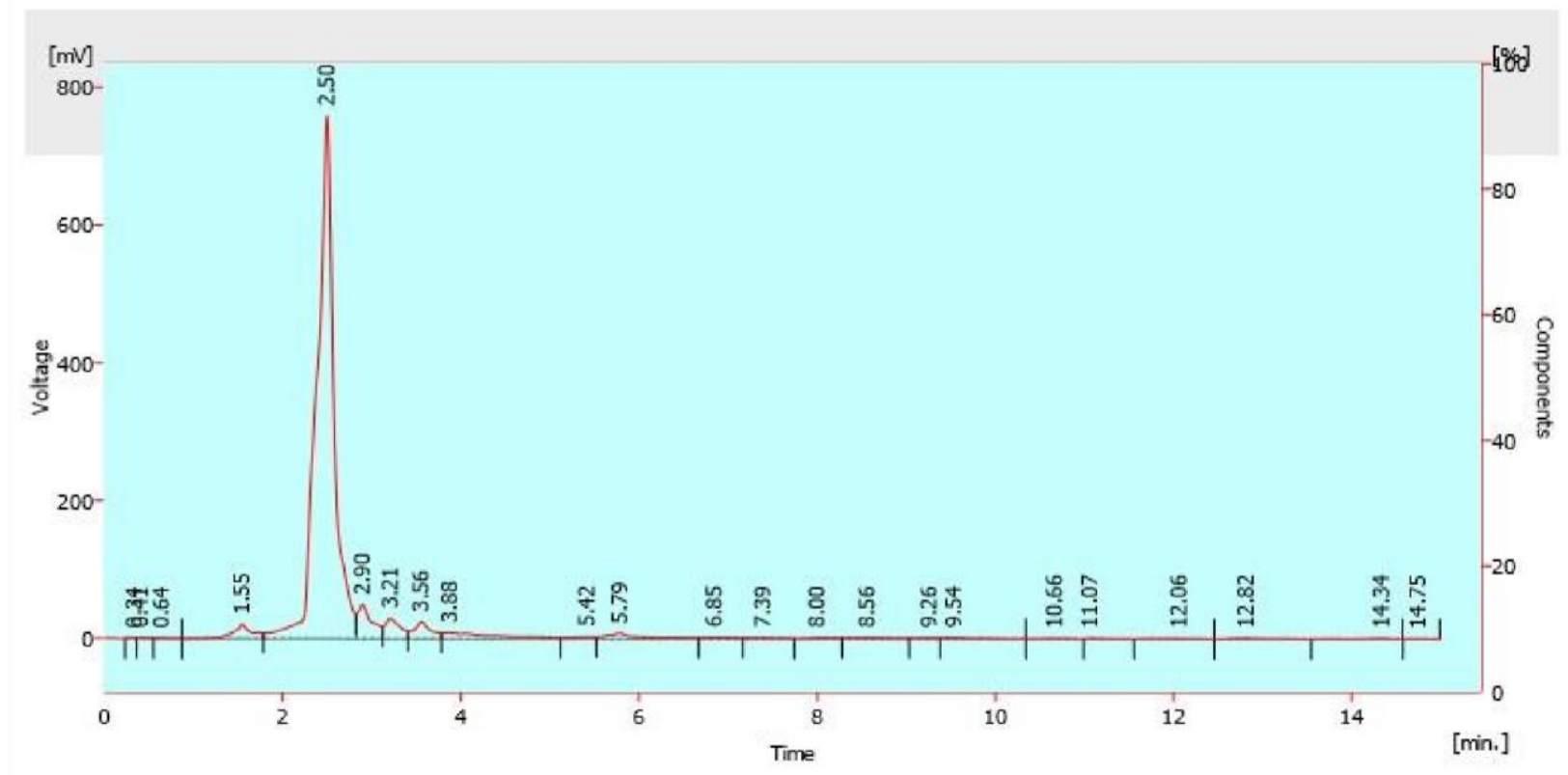

\section{Chromatogram of $\mathrm{TN}_{1} \mathrm{D}_{4} 1$}

\section{REFRENCES}

1. Infectious Diseases Society of America (IDSA). (2011). Combating antimicrobial resistance: policy recommendations to save lives. Clinical Infectious Diseases, 52(suppl_5), S397-S428.

2. Vardakas, K. Z., Rafailidis, P. I., Konstantelias, A. A., \& Falagas, M. E. (2013). Predictors of mortality in patients with infections due to multi-drug resistant Gram negative bacteria: the study, the patient, the bug or the drug?. Journal of Infection, 66(5), 401-414.

3. Bodi, M., Ardanuy, C., \& Rello, J. (2001). Impact of Gram-positive resistance on outcome of nosocomial pneumonia. Critical care medicine, 29(4), N82-N86.

4. Perez, F., \& Van Duin, D. (2013). Carbapenem-resistant Enterobacteriaceae: a menace to our most vulnerable patients. Cleveland Clinic journal of medicine, 80(4), 225.

5. Ena, J., Dick, R. W., Jones, R. N., \& Wenzel, R. P. (1993). The epidemiology of intravenous vancomycin usage in a university hospital: a 10-year study. Jama, 269(5), 598-602.

6. Costerton, J. W., Stewart, P. S., \& Greenberg, E. P. (1999). Bacterial biofilms: a common cause of persistent infections. Science, 284(5418), 1318-1322.

7. Davies, J., \& Davies, D. (2010). Origins and evolution of antibiotic resistance. Microbiology and molecular biology reviews, 74(3), 417-433.

8. Giedraitienè, A., Vitkauskienè, A., Naginienè, R., \& Pavilonis, A. (2011). Antibiotic resistance mechanisms of clinically important bacteria. Medicina, 47 (3), 19.

9. Reidy, B., Haase, A., Luch, A., Dawson, K. A., \& Lynch, I. (2013). Mechanisms of silver nanoparticle release, transformation and toxicity: a critical review of current knowledge and recommendations for future studies and applications. Materials, 6(6), 2295-2350.

10. Codex, P. (1979). Incorporating the British Pharmaceutical Codex.

11. Nascimento, G. G., Locatelli, J., Freitas, P. C., \& Silva, G. L. (2000). Antibacterial activity of plant extracts and phytochemicals on antibiotic-resistant bacteria. Brazilian journal of microbiology, 31, 247-256.

12. Grundmann, H., Aires-de-Sousa, M., Boyce, J., \& Tiemersma, E. (2006). Emergence and resurgence of meticillinresistant Staphylococcus aureus as a public-health threat. The lancet, 368(9538), 874-885.

13. David, M. Z., \& Daum, R. S. (2010). Community-associated methicillin-resistant Staphylococcus aureus: epidemiology and clinical consequences of an emerging epidemic. Clinical microbiology reviews, 23(3), 616-687. 
14. Drlica, K. (2001). A strategy for fighting antibiotic resistance. ASM news, 67, 27-33.

15. Nikaido, H. (2009). Multidrug resistance in bacteria. Annual review of biochemistry, 78, 119-146.

16. Ventola, C. L. (2015). The antibiotic resistance crisis: part 1: causes and threats. Pharmacy and therapeutics, 40(4), 277.

17. Allen, H. K., Donato, J., Wang, H. H., Cloud-Hansen, K. A., Davies, J., \& Handelsman, J. (2010). Call of the wild: antibiotic resistance genes in natural environments. Nature Reviews Microbiology, 8(4), 251-259..

18. Ventola, C. L. (2015). The antibiotic resistance crisis: part 1: causes and threats. Pharmacy and therapeutics, 40(4), 277

19. Jacobsen, F., Fisahn, C., Sorkin, M., Thiele, I., Hirsch, T., Stricker, I., ... \& Steinstraesser, L. (2011). Efficacy of topically delivered moxifloxacin against wound infection by Pseudomonas aeruginosa and methicillin-resistant Staphylococcus aureus. Antimicrobial agents and chemotherapy, 55(5), 2325-2334.

20. Yilmaz, M., Soran, H., \& Beyatli, Y. (2006). Antimicrobial activities of some Bacillus spp. strains isolated from the soil. Microbiological research, 161(2), 127-131.

21. Gebreel, H. M., El-Mehalawy, A. A., El-Kholy, I. M., Rifaat, H. M., \& Humid, A. A. (2008). Antimicrobial activities of certain bacteria isolated from Egyptian soil against pathogenic fungi. Research Journal of Agriculture and Biological Sciences, 4(4), 331-339.

22. Hilty, D. M., Ferrer, D. C., Parish, M. B., Johnston, B., Callahan, E. J., \& Yellowlees, P. M. (2013). The effectiveness of telemental health: a 2013 review. Telemedicine and e-Health, 19(6), 444-454.

23. Sun, J., Deng, Z., \& Yan, A. (2014). Bacterial multidrug efflux pumps: mechanisms, physiology and pharmacological exploitations. Biochemical and biophysical research communications, 453(2), 254-267.

24. Abbot, P., Abe, J., Alcock, J., Alizon, S., Alpedrinha, J. A., Andersson, M., ... \& Zink, A. (2011). Inclusive fitness theory and eusociality. Nature, 471(7339), E1-E4.

25. Hu, J., Chen, G., \& Lo, I. M. (2005). Removal and recovery of Cr (VI) from wastewater by maghemite nanoparticles. Water research, 39(18), 4528-4536.

26. Ayyadurai, N., Ravindra Naik, P., Sreehari Rao, M., Sunish Kumar, R., Samrat, S. K., Manohar, M., \& Sakthivel, N. (2006). Isolation and characterization of a novel banana rhizosphere bacterium as fungal antagonist and microbial adjuvant in micropropagation of banana. Journal of Applied Microbiology, 100(5), 926-937.

27. Al-Dhabi, N. A., Esmail, G. A., Duraipandiyan, V., Arasu, M. V., \& Salem-Bekhit, M. M. (2016). Isolation, identification and screening of antimicrobial thermophilic Streptomyces sp. Al-Dhabi-1 isolated from Tharban hot spring, Saudi Arabia. Extremophiles, 20(1), 79-90.

28. Mezaache-Aichour, S., Guechi, A., Zerroug, M. M., Nicklin, J., \& Strange, R. N. (2013). Antimicrobial activity of Pseudomonas secondary metabolites. Pharmacognosy Communications, 3(3).

29. Sunkar, S., \& Nachiyar, C. V. (2013). Endophytic fungi mediated extracellular silver nanoparticles as effective antibacterial agents. Int J Pharm Pharm Sci, 5(2), 95-100.

30. Isnansetyo, A., \& Kamei, Y. (2003). MC21-A, a bactericidal antibiotic produced by a new marine bacterium, Pseudoalteromonas phenolica sp. nov. O-BC30T, against methicillin-resistant Staphylococcus aureus. Antimicrobial agents and chemotherapy, 47(2), 480-488.

31. Commare, R. R., Nandakumar, R., Kandan, A., Suresh, S., Bharathi, M., Raguchander, T., \& Samiyappan, R. (2002). Pseudomonas fluorescens based bio-formulation for the management of sheath blight disease and leaffolder insect in rice. Crop Protection, 21(8), 671-677.

32. Garcia-Rosales, C., Eckstein, W., \& Roth, J. (1995). Revised formulae for sputtering data. Journal of Nuclear Materials, 218(1), 8-17.

33. Zhou, M., Li, L., Dunson, D., \& Carin, L. (2012). Lognormal and gamma mixed negative binomial regression. In Proceedings of the... International Conference on Machine Learning. International Conference on Machine Learning (Vol. 2012, p. 1343). NIH Public Access.

34. Saravanan, T., \& Muthusamy, M. (2006). Influence of Fusarium oxysporum f. sp. cubense (ef smith) Snyder and Hansen on 2, 4-diacetylphloroglucinol production by Pseudomonas fluorescens migula in banana rhizosphere. Journal of plant protection research, 241-253. 